\title{
LA POLÍTICA INTERNACIONAL DE SALVADOR ALLENDE HACIA BOLIVIA (1970-1973)
}

\author{
SALVADOR ALLENDE'S FOREING POLICY TOWARDS BOLIVIA \\ (1970-1973)
}

Milton Cortés Díaz*

\begin{abstract}
Este artículo describe las actitudes y políticas de Salvador Allende hacia Bolivia, desde sus días de parlamentario hasta la política exterior de su gobierno. Planteamos que, durante su mandato, Chile desarrolló una estrategia que mezcló pragmatismo con ideología, tratando de restablecer relaciones diplomáticas con La Paz a cambio de abrir discusiones acerca de la aspiración boliviana al mar. Allende aprovechó la cercanía ideológica que tenía con el gobierno de Juan José Torres para generar confianza entre los dos gobiernos, aunque la estrategia resultó contraproducente cuando un gobierno ideológicamente hostil tomó el poder en La Paz, lo que nuevamente condujo a un deterioro en las relaciones.
\end{abstract}

Palabras claves: Salvador Allende, relaciones chileno-bolivianas, demanda marítima boliviana.

This article describes the attitudes and policies of Salvador Allende towards Bolivia, from his days as a congressman until the end of his administration. We posit that during his presidency Chile developed a strategy that mixed pragmatism and ideology, trying to reestablish diplomatic relations with La Paz in exchange for an open discussion on the Bolivian aspiration an access to the sea. Allende took advantage of the ideological affinity with the government of Juan José Torres to generate trust between the two governments. However, this strategy backfired when a hostile ideological government took power in La Paz, which led, once again, to a deterioration of relations.

Key words: Salvador Allende, chilean-bolivian relations, bolivian aspiration to the sea.

\section{Introducción}

En la historia de las relaciones chileno-bolivianas, los años del gobierno de Salvador Allende (1970-1973) han sido relativamente poco estudiados. Recientemente han aparecido testimonios que manifestarían que Allende estuvo dispuesto a otorgarle una salida al mar a Bolivia, lo que nos ha impulsado a escribir el presente trabajo, para ayudar a establecer, mediante fuentes históricas, cuál fue la política efectivamente seguida por su administración.

En este caso también encontramos la particularidad de ser un gobierno que manifestaba en su política exterior un lenguaje ideológico, teniendo como ejes el antiimperialismo, el anticapitalismo y latinoamericanismo de izquierdas, que convivía al mismo tiempo con una actitud pragmática y realista, destinada a evitar conflictos que hicieran peligrar su proyecto de transformaciones radicales en lo interno (Sánchez Fuentes, 2015 y San Francisco, et al., 2019, pp. 579-599). Nuestra hipótesis de investigación es que esta tensión se mostró particularmente en el caso boliviano, en donde Allende realizó gestiones con el gobierno de Juan José Torres para un restablecimiento de las relaciones diplomáticas a cambio de abrir gestiones respecto de su aspiración portuaria, en lo que se mezcló una cercanía ideológica con una gran dosis de pragmatismo.

Como se había adelantado, la bibliografía de este período es escasa. Algunos trabajos le dan algunas pocas páginas a esta época en el marco de obras de carácter general. Entre ellas encontramos a Fermandois (1985), quien enfatiza sobre todo el aspecto ideológico que adoptó la relación, y a Gumucio Granier (1985), que se enfoca en las gestiones confidenciales del tema marítimo. Un libro que produjo cierto revuelo, Salvador Allende ¡Mar para Bolivia! (Taboada, 2004), afirma que el mandatario chileno le expresó al autor de la obra, que deseaba, sin pedir nada a cambio, darle mar a Bolivia. Sin embargo, el que la versión de la entrevista publicada por el autor en 1971 no hiciera

\footnotetext{
* Universidad San Sebastián. Santiago, Chile. Correo electrónico: milton.cortes@uss.cl
} 
mención a esta espectacular oferta nos hace dudar de su veracidad (Taboada, 1971). Los argumentos de Taboada motivaron una réplica del entonces canciller chileno Heraldo Muñoz, quien dijo que "lo que hay aquí respecto al presidente Allende y Bolivia es un debate para los historiadores", pero que "lo que sí está medianamente claro es que durante la presidencia de Salvador Allende la política de Estado se mantuvo y fue estricto en el respeto a los tratados internacionales, específicamente el de 1904" (El Mostrador, 22 febrero de 2015). Por último, debemos mencionar la tesis de Belmonte Pijuán (2012), que trata con mayor extensión parte del período estudiado, particularmente mediante la diplomacia pública de uno de sus protagonistas, el canciller boliviano Mario Gutiérrez.

Respecto de las fuentes, se utilizarán principalmente aquellas de carácter público, en particular sesiones del Senado y prensa de la época. Asimismo, se aprovecharán los testimonios públicos de algunos personajes que participaron en las gestiones. Los archivos del Ministerio de Relaciones Exteriores de Chile pertinente a Bolivia tienen un carácter reservado, sin embargo, hemos podido suplir en parte esta falta con el uso de documentos publicados durante el juicio de Chile y Bolivia en La Haya, si bien la mayoría son de parte boliviana, por lo que hay que tratar sus afirmaciones con cierta cautela, a la espera de la apertura de los archivos chilenos.

Si bien el trabajo se concentra en las relaciones diplomáticas, también adopta de la historia de las relaciones internacionales la idea que las relaciones van más allá de lo meramente estatal, lo que incluye el estudio de las ideas políticas, por lo que analizaremos el discurso de Allende frente a Bolivia antes de su llegada a la presidencia, como asimismo la influencia de la prensa y otros grupos de presión en las relaciones bilaterales.

\section{Salvador Allende y Bolivia}

Una de las primeras intervenciones parlamentarias de Salvador Allende concerniente a Bolivia, hecha en octubre de 1945, trata precisamente respecto de la aspiración portuaria, pero sin manifestarse a favor o en contra, limitándose a pedir un debate a la altura de las circunstancias: "El problema del puerto a Bolivia no puede tratarse con el criterio superficial de un comerciante de puertas y ventanas, sino con la alta responsabilidad que emana de un problema de esta naturaleza" (APSA, III, p. 138).
Por lo general, sus intervenciones sobre Bolivia trataban sobre los regímenes políticos en el altiplano. Mostró una animadversión inicial al proyecto político del Movimiento Nacionalista Revolucionario, que asociaba a tendencias dictatoriales y fascistas. Así comentó en febrero de 1947: "yo alcé mi voz para condenar enérgicamente el Gobierno del señor Villarroel, qué había destruido las libertades públicas en su país y perseguido a obreros, estudiantes e intelectuales" (APSA, III, p. 231). En otra oportunidad calificó la guerra civil de 1949, impulsada por el MNR, como: "Una sublevación militar, apoyada en un sector civil de vieja raigambre totalitaria, amaga la estabilidad del Gobierno de Bolivia, y lo que comenzó como un conato es probable que pueda transformarse en una guerra civil" (III, p. 663). Acusaba que la revuelta formaría parte un plan internacional en contra Chile, que quedaría envuelto "por un círculo de hierro formado por la Argentina de Perón, el Perú de Odría, y Bolivia de Paz Estenssoro y sus satélites" (APSA, III, p. 664).

La visión de Allende acerca del MNR cambiaría con el tiempo, al asociarse a la Revolución Boliviana con una izquierda nacionalista. Allende expresaría en 1960 que "la revolución de Bolivia es antiimperialista y antifeudal; nacionalizó las minas de estaño, hizo la reforma agraria y armó al campesinado boliviano" (Diario de Sesiones del Senado, 13 de septiembre de 1960, p. 2964). En 1961, Allende realizó una visita a Bolivia, junto con el senador Jonás Gómez, en representación del Partido Socialista con motivo de la celebración del aniversario de la revolución. Allí se reunió con importantes figuras de la vida pública boliviana, incluyendo al presidente Hernán Siles y al exmandatario Víctor Paz Estenssoro. Ambos senadores, junto con Federico Fortún Sanjinés (en representación del MNR), decidieron subscribir una declaración en favor del acercamiento de ambos pueblos, enfatizando el intercambio comercial y cultural.

No se tocó el tema del Lauca ni la cuestión portuaria. "No se nos mencionó, tampoco, el problema del mar, salvo por Paz Estenssoro, para decir que había dejado de ser problema; que era asunto superado, un pretexto de agitación de los reaccionarios bolivianos, de la 'rosca derechista', de los consorcios mineros, para sojuzgar al pueblo boliviano", explicaría posteriormente Gómez (Diario de Sesiones del Senado, 24 de junio de 1964).

La declaración no fue dada a conocer a la prensa sino hasta 1964, creando críticas por parte de la 
prensa conservadora, que atacaban a Allende diciendo que era favorable a las aspiraciones marítimas de Bolivia. En respuesta, Allende dijo que su posición personal de Bolivia era de "una claridad absoluta", asumiendo la resolución del comité central de su partido, el Socialista, en que se criticaba cómo el gobierno chileno había manejado la cuestión del Lauca y se condenaba "toda exacerbación de sentimientos chauvinistas, destinada a provocar o resucitar querellas entre nuestros países debilita la acción solidaría de las clases explotadas en su lucha por la liberación social y nacional y prolonga el sentimiento continental adverso a la dirección norteamericana”. En último término, para el PS:

las condiciones para una verdadera convivencia pacífica inter latinoamericana y para la eliminación definitiva de los factores de fricción entre nuestras naciones, solo podrán establecerse cuando cada pueblo logre liberarse de las minorías gobernantes que alientan la división y los conflictos para prolongar su dominio de clase y cuando se establezcan las bases de una integración democrática de los pueblos actualmente sometidos. (APSA, VIII, P. 372)

En realidad, esto aclaraba poco. Puede desprenderse del texto del PS que hay una postergación a discutir el tema portuario, hasta que ambos países tuvieran gobiernos de izquierda que terminasen con el predominio de "minorías dominantes". Allende sigue esta estela en el sentido de que nunca se pronunció abiertamente ni a favor ni en contra de la demanda marítima boliviana.

\section{Relaciones chileno-bolivianas previas a 1970}

Las relaciones chileno-bolivianas se habían mantenido en buen pie durante los gobiernos de Carlos Ibáñez y Víctor Paz Estenssoro, en donde la demanda boliviana por una salida al mar estuvo ausente, prefiriéndose realizar esfuerzos por una mejor complementación económica. Esto cambió con la presidencia de Jorge Alessandri (1958-1964), quien no solo carecía de la sintonía ideológica de su predecesor con los gobiernos de la Revolución Boliviana, sino que además adoptó una dura posición frente a la controversia por el uso de las aguas del río Lauca, lo que derivó, el 15 de abril de 1962, en que Bolivia rompiera relaciones con Chile. Se sucedieron una serie de gestiones para reanudar el diálogo, particularmente con la participación de la OEA, pero Bolivia puso como condición la resolución de su aspiración portuaria. Este condicionamiento pasaría a ser una política consistente del altiplano que se mantendría en los gobiernos siguientes (San Francisco et al., 2016, pp. 227-235). Desde Chile, esta clase de postura se ha percibido como una instrumentalización, un aprovechamiento de las elites bolivianas del tema marítimo para obtener ganancias políticas internas, lo que dificultó aún más una posible solución (Otero y Rivas, 2018).

Durante el gobierno de Eduardo Frei Montalva se realizaron diversas gestiones para lograr el restablecimiento de las relaciones diplomáticas. Aunque Chile estaba dispuesto a resolver la cuestión del Lauca y dar compensaciones a Bolivia por eventuales perjuicios, esta salida quedó bloqueada al mezclarse siempre con la aspiración marítima. Hacia 1968 se hizo una gestión importante, bajo la idea de crear un polo de desarrollo en Arica y satisfacer necesidades económicas y sociales de los tres países, en una idea que también era recurrente dentro de la sociedad civil (Ovando, 2015). Para ese objetivo, en Chile se estudió una propuesta en "que a cambio de una cesión por cien años de parte de las aguas del Lago Titicaca, Perú y Bolivia gozarían durante el mismo período de iguales derechos que Chile en el Territorio de Arica, sin perjuicio de conservar este último su dominio sobre él" (San Francisco, et al., 2018, pp. 432-434). La proposición tuvo una recepción positiva en Bolivia, pero, según Gabriel Valdés - cuyo testimonio debe tomarse con cautela-, el gobierno de Frei decidió darle fin tras la victoria de Allende, pues el gobierno boliviano estimó que podía obtener más de lo hasta entonces alcanzado con el próximo presidente (Gabriel Valdés, 2009, pp. 174-177).

En el mes previo a que Allende asumiera la presidencia de la República, en Bolivia se vivieron graves turbulencias políticas producto de un intento de golpe de Estado contra el general Alfredo Ovando. El golpe fracasó por la respuesta de la fracción más izquierdista del Ejército, lo que llevó a la renuncia de Ovando y la llegada a la presidencia del general Juan José Torres. Este establecería un gobierno de izquierda nacionalista con un programa de transformaciones radicales, que en política exterior se reflejó en un distanciamiento con Estados Unidos. Tanto en los 
aspectos internos como internacionales, el nuevo gobierno boliviano era el que más se asemejaba en el continente al de Salvador Allende, por lo que resultó natural que personeros de ambos gobiernos tuvieran una mayor simpatía recíproca, abriéndose nuevas posibilidades para un entendimiento que llevara al restablecimiento de relaciones.

\section{Un acercamiento con sustento ideológico}

La evidencia disponible parece indicar que la estrategia del gobierno de Allende para reanudar relaciones con Bolivia se sustentó en lo que había realizado su antecesor. El 24 de septiembre de 1970, el canciller boliviano, Edgardo Camacho, insistió en las Naciones Unidas en su disposición a lograr un "entendimiento honorable y constructivo" con Chile respecto de su demanda de salida al mar ( $E l$ Mercurio, 25 de septiembre de 1970). No obstante, al regresar a su país, se mostró una apertura al indicar que este tema no sería un obstáculo para iniciar negociaciones, afirmando que "no impondremos condiciones ni las aceptaremos para reanudar relaciones" (El Mercurio, 1 de octubre de 1970).

Quizás con ello se quería preparar a la opinión pública de su país para el resultado de una gestión que se venía realizando desde la presidencia de Frei. En contraste con el anteriormente citado testimonio de Gabriel Valdés, un documento boliviano de la época indica que en las negociaciones, que duraron 10 meses, "se arribó a concretas conclusiones con el gobierno democratacristiano del Presidente Frei, las cuales han sido plenamente aprobadas por el gobierno de la Unidad Popular". Las condiciones acordadas implicaban una declaración conjunta en donde se restauraban las relaciones, junto con la formación de comisiones mixtas para tratar el tema del Lauca y la creación de un terminal marítimo boliviano en Arica. Con el gobierno de Frei se habría llegado a un acuerdo en el sentido de que, tras la reanudación de relaciones, Bolivia enviaría a Chile un oficio pidiendo "continuar con las negociaciones especificadas en las Notas de Gobierno de 1 y 20 de junio de 1950". El gobierno de Allende habría mirado como un avance lo acordado durante Frei, estando de acuerdo que el intercambio de notas se produciría 15 días después de reanudadas las relaciones (International Court of Justice, 2017, vol. 3, pp. 650-660).

A principios de 1971 se comenzaron a suceder ciertas declaraciones públicas que apuntaban a una reanudación de relaciones. El 27 de enero, el canciller boliviano, general Emilio Molina Pizarro, declaró que había un ambiente propicio para un entendimiento con el gobierno y pueblos chilenos, pero que "eso podrá ser posible siempre y cuando no vaya en contra de las nobles y sagradas aspiraciones del pueblo boliviano", es decir, la cuestión marítima. El senador Teitelboim, que había viajado a Bolivia por esos días, dijo el 8 de febrero que "El Gobierno del Presidente Allende está dando algunos pasos vinculados directamente con la reanudación de relaciones" (La Tercera, 20 de febrero de 1971). Al día siguiente, el canciller boliviano se refirió a ello, expresando que "Bolivia no pone condiciones previas a la reanudación de relaciones diplomáticas con Chile". Sin embargo, pronto cambió su discurso, rectificando que "este contacto directo debe contemplar el anhelo boliviano de una salida marítima por el Pacífico" (La Tercera, 20 de febrero de 1971). Por su parte, el Canciller Almeyda respondió a los gestos de su par boliviano y expresó que ellos "corresponden al pensamiento de la Cancillería chilena en estas materias y son un paso adelante para normalizar estas relaciones que nunca debieron de romperse" (La Tercera, 13 de febrero de 1971).

Teitelboim dijo que observó en los bolivianos un "ferviente deseo de poner en marcha una integración efectiva con Chile y que se tiene mucho interés por el área comercial del norte especialmente en Arica". Confirmó a la prensa que realizó una entrevista con el general Torres, si bien la presentó como una "conversación improvisada e informal, sin agenda, [que] podía considerarse un paso más. Pero faltan muchos pasos todavía" (El Mercurio, 13 de febrero de 1971). En forma retrospectiva, Teitelboim revelaría que el objetivo de su viaje era sostener reuniones con el presidente Torres y el canciller Huáscar Taborga para lograr la reanudación de relaciones, lo que incluía una discusión respecto del tema del mar:

se había pensado en la posibilidad de establecer una especie de corredor al norte de Bolivia, entre la frontera peruana, al norte de Arica. Es una superficie pequeña, relativamente pequeña, de unos cuantos kilómetros. Pero de todas maneras se podía establecer una especie de corredor que permitiera la salida de Bolivia al mar, donde Bolivia pudiese tener un pequeño puerto, una cosa así. A parte de ventajas 
desde el punto de vista portuario en Arica, en Iquique y en Antofagasta, en los puertos del norte (Magasich, 2014).

Teitelboim mencionó como uno de los principales incentivos para las negociaciones el temor a una posible guerra con Perú y Bolivia que cundía entre los militares chilenos, ante la proximidad del centenario de la Guerra del Pacífico. Asimismo, explica que la cuestión de los militares dificultaba alcanzar un acuerdo con Bolivia: "porque eso significaba para el gobierno de Allende un paso muy delicado. Porque eso podía ser el estallido, la justificación del golpe: un gobierno que entrega parte del territorio nacional es 'antipatriótico'. Estaba el problema del Ejército” (Magasich, 2014).

El gobierno boliviano comenzó a dar una dimensión ideológica al posible restablecimiento de relaciones. La emisora estatal, Radio Illimani, expresó que, sin chauvinismo ni patrioterismos, los bolivianos esperaban reconquistar el mar no por la vía bélica, sino que por la "comprensión revolucionaria" de dos pueblos, "embarcados en un mismo camino: la liberación nacional" y un enemigo en común, "el imperialismo" (La Prensa, 22 de marzo de 1971). La Central Obrera Boliviana, principal organización sindical del país, declaró que "luchará intransigentemente hasta imponer la reanudación de relaciones diplomáticas con Chile", ya que con ello se "tonificará al movimiento revolucionario latinoamericano y al boliviano en particular" ( $\mathrm{La}$ Prensa, 22 de marzo de 1971).

Con ocasión del día del mar, el presidente Torres anunció: "Volveremos al mar, porque el derecho y la justicia están de nuestro lado, y porque nuestra presencia sobre el Pacífico afirma la soberanía y la liberación del país". El método para este retorno debería ser una "negociación sobre bases justas que reconozcan su pleno e indiscutible derecho" (El Mercurio, 24 de marzo de 1971).

Paralelo a la cuestión portuaria se realizaron gestiones de integración económica. En marzo, el gobierno boliviano pidió a Chile que Iquique fuera puerto franco para Bolivia, lo que daría gran importancia al camino Oruro-Iquique, que se había empezado a construir (El Mercurio, 14 de marzo de 1971). El trabajo de la Comisión Mixta de Transporte Chileno-Boliviana también fue otra instancia de cooperación a nivel técnico, manteniéndose tarifas preferenciales que satisfacían a ambos países $(E l$ Mercurio, 7 de diciembre de 1971).
Una fuente de críticas a la posible reanudación de relaciones la presentó la organización boliviana Acción Marítima, que afirmaba que esta no se podía realizar "hasta que no se abra diálogo portuario con la garantía de nuestro acceso al mar y no ofrecernos rendidos y humillados en incondicionales relaciones de amistad u paz con el usurpador" ( $L a$ Tercera, 17 de febrero de 1971). También en la prensa boliviana hubo una campaña en contra de este posible acercamiento. El matutino Presencia, el de mayor circulación del país, criticó a quienes buscaban tener relaciones con Chile como medio de fortalecer la unidad latinoamericana, que veía como un truco para persuadir "que la demanda portuaria de Bolivia no tiene significación práctica ante la conveniencia de sustituirla con la integración regional y que esa demanda habrá de desaparecer de la discusión porque es de menor importancia" (La Tercera, 17 de febrero de 1971). Advertía que "la diplomacia de nuestro vecino no ha cambiado absolutamente nada" y que reanudar relaciones sin que Chile hiciera "un gesto práctico" equivaldría a decir que Bolivia se equivocó al interrumpirlos (La Prensa, 8 de agosto de 1971). El partido Falange Socialista dirigió una carta al canciller en que afirmaba que "es perentorio lograr la revisión del ominoso tratado de 1904, por el cual Bolivia fue obligada a aceptar la pérdida de su litoral" ( $\mathrm{La}$ Tercera, 18 de febrero de 1971).

Los acercamientos entre los dos gobiernos tendían a una reanudación de relaciones que parecía cercana a materializarse. Durante la Asamblea General Ordinaria de la OEA, realizada en Costa Rica en abril de 1971, se desarrolló una reunión entre el canciller chileno Clodomiro Almeyda y su par boliviano Huáscar Taborga. De acuerdo con la documentación boliviana, en ese encuentro el tema central fue el restablecimiento de relaciones diplomáticas "sobre la base de negociaciones para lograr un acceso propio y soberano al Pacífico para Bolivia y otros asuntos". Taborga indicó que su gobierno planteaba como solución "un corredor al norte de Arica, siguiendo la frontera, incluidas la vía férrea y un muelle. Asimismo, reiteró la necesidad de un enclave soberano en Mejillones". El procedimiento para el restablecimiento de relaciones sería mediante una declaración conjunta, en la que se actualizarían las notas de 1950. Se discutió también un eventual sondeo previo al Perú. Almeyda aprobó el mecanismo, siempre y cuando ello no afectase el restablecimiento de 
relaciones (International Court of Justice, 2017, vol. 3, pp. 664-668).

Una versión chilena de este encuentro lo da Mario Valenzuela Lafourcade, que en esos tiempos era Director de Política Exterior. En ella, el canciller Almeyda se mostró abierto a una proposición boliviana de acceso soberano al mar, pidiendo a ese país que, aprovechando las circunstancias de cercanía política entre los tres gobiernos, obtuviera seguridades que Perú no vetaría un posible acuerdo respecto de un corredor al norte de Arica, para evitar el fracaso de las notas de 1950 (El Mercurio, 13 de julio de 2006). Al día siguiente del encuentro, el canciller Almeyda pronunció un discurso ante la OEA, en la que se refirió a las relaciones con Bolivia: "Queremos restablecer relaciones diplomáticas con Bolivia, convencidos de que la actual situación de nuestros países no tiene justificación ante nuestros pueblos y ante la historia" (Almeyda, 1971, p. 192).

Le correspondió al cónsul boliviano Frank Ruck presentar en Santiago el modelo de declaración conjunta. Lo entregó a la Cancillería chilena el 13 de agosto, siendo sus puntos centrales la reanudación de relaciones y la apertura de negociaciones pertinente a la mediterraneidad boliviana. Entre los otros temas abordados, se anunciaría la creación de una Comisión Técnica Mixta encargada de estudiar el problema de las aguas del río Lauca, así como de otra comisión dedicada a estudiar las posibilidades de complementación económica, cuyos principales temas serían: las condiciones en que Chile adquiría estaño y petróleo de Bolivia; la suscripción de un tratado de comercio; facilidades al tránsito de personas y mercancías; la eliminación de pasaportes y visas. Otro aspecto relevante era la creación de un terminal marítimo boliviano en Arica, a cargo de una agencia aduanera (International Court of Justice, 2017, vol. 3, pp. 672-674). Desconocemos la respuesta de Chile, si es que alcanzó a elaborar, porque Torres fue derrocado por un golpe de Estado el 21 de agosto. Según una versión entregada por Ruck, en las gestiones realizadas el 13 de agosto se habría llegado a un acuerdo para que Allende llamase a Torres por teléfono desde Arica el 23 de agosto, previo a su gira por los países del Pacto Andino, para hablar de la reanudación de relaciones y la negociación marítima. Asimismo, durante su viaje, Allende conversaría con el presidente peruano Velasco Alvarado acerca de la necesaria cooperación peruana para resolver la mediterraneidad de Bolivia (Gumucio Granier, 1985, p. 539).
Siempre según Rück, la discusión de fondo ya había sido adelantada con Almeyda y sus principales puntos comprendían:

1) petróleo boliviano para Chile; 2) gas, por una derivación del gasoducto que une a Bolivia a Argentina; 3) dos caminos, uno de ellos para la provisión de ganado y productos de la agricultura desde Santa Cruz. Y por la parte de Chile, la franja de 10 kilómetros de ancho, al sur de la frontera con Perú y un muelle en Arica, bajo bandera boliviana y con atención de su personal nacional, uniformado y ejerciendo todos los actos propios de la carga y descarga de buques (Yofre, 2000, p. 219).

Durante algunas intervenciones públicas, el presidente Allende se había referido a las relaciones con Bolivia, pero siempre con un tono muy comedido. En su mensaje ante el Congreso dijo "La situación anómala de nuestras relaciones con la República de Bolivia contradice la vocación de ambos pueblos, por lo que haremos cuanto esté de nuestra parte para normalizarla"1. En otra oportunidad, ante la pregunta de un periodista argentino, que lo instaba a responder por la demanda boliviana por una salida al mar, el Presidente chileno manifestó: "Debo contestarle que el gobierno de Chile es respetuoso de los compromisos y de los tratados. Pero debo anticiparle, que es nuestro propósito restablecer las relaciones diplomáticas, comerciales y culturales, al más breve plazo con Bolivia" (Allende, 1978, p. 20).

\section{Golpe de Estado en Bolivia. La reacción en Chile}

El derrocamiento de Juan José Torres y la llegada al poder de Hugo Banzer, con un gobierno de marcado signo anticomunista, llevó a la prensa chilena a realizar diferentes interpretaciones de lo acaecido. El Mercurio hizo notar que, a diferencia de otras ocasiones, las Fuerzas Armadas actuaron unidas, así como del marcado carácter anticomunista del nuevo gobierno, con más parecido al caso brasileño que al peruano (El Mercurio, 23 de agosto de 1971). Este diario, junto con el democratacristiano La Prensa, responsabilizaba de la crisis a la acción de la ultraizquierda, especialmente dos de sus iniciativas, la Asamblea Popular y la creación de 
milicias populares, vistas como infiltración marxista en el ejército (La Prensa, 23 de agosto de 1971).

Los partidos de izquierda caracterizaron de inmediato al nuevo gobierno de Banzer como fascista y "gorila", achacando el golpe a la mano de la CIA y al imperialismo, que manejaría a los sectores reaccionarios y antipatriotas bolivianos, en lo que era un esfuerzo por aplastar a los pueblos e imponer la contrarrevolución en América Latina (Clarín, 21 y 23 de agosto de 1971). Este punto lo remarcó también El Siglo, al advertir que era evidente "que la maniobra está destinada a debilitar la posición internacional de nuestro propio país... para nadie es un misterio que el imperialismo quisiera tender un cordón 'sanitario' en torno a un país que, como el nuestro, pone sus fuerzas en tensión para construir una nueva sociedad" (El Siglo, 22 de agosto de 1971).

A pesar de la derrota, en la prensa de izquierda se mostró como heroica la resistencia del pueblo boliviano contra el golpe. El diario oficialista $\mathrm{La}$ Nación decía que "quedará como herencia un pueblo hecho de mineros, campesinos y estudiantes armados, además de los soldados progresistas... hay un pueblo en armas" (La Nación, 23 de agosto de 1971), pero se estimaba, en palabras de El Siglo, que "a esa resistencia le faltó el apoyo militar" (El Siglo, 23 de agosto de 1971). Acerca de lo que vendría a futuro, Clarín consideraba que "los trabajadores bolivianos no tienen otra alternativa que reemprender de inmediato, sin ilusiones y con firmeza, la lucha clandestina e insurreccional armada, capaz de aventar del Palacio Quemado a los sepultureros de turno" (Clarín, 24 de agosto de 1971).

Por su parte, el presidente Allende, que se encontraba en Quito al ser derrocado Torres, hizo mención de la situación boliviana ante la pregunta de un periodista, en cuanto a si los hechos en el altiplano afectarían de alguna forma a Chile. Respondió: "Lamentablemente, no tenemos relaciones ni diplomáticas ni comerciales con Bolivia. Somos partidarios de tenerlas. Eso sí, de acuerdo a los tratados y compromisos y no sobre la base de imposiciones" (Allende, 1978, p. 50).

\section{Tensión por la cuestión marítima}

La prensa chilena afirmó que el golpe de Estado interrumpió un inminente restablecimiento de relaciones, en la que el canciller boliviano se entrevistaría con Allende en Arica para tomar los últimos acuerdos que la permitieran. La reacción oficial de La Moneda frente al golpe fue de desear que "estos cambios no alteren los deseos de ambos pueblos de que los Gobiernos reanuden sus relaciones" (La Prensa, 25 de agosto de 1971). No había necesidad de plantearse el tema del reconocimiento, pues ello solo se aplicaba a los países con que se mantenían relaciones.

No obstante, el nuevo régimen boliviano implicó un grave problema, pues Banzer reinició con fuerza la demanda boliviana por una salida al mar, colocándola como condición fundamental para cualquier reinicio de relaciones. Dijo en una de sus primeras conferencias de prensa: "El pueblo boliviano tiene un objetivo sentimental y práctico: la recuperación marítima. Esta es la primera condición fundamental que los bolivianos exigimos para cualquier negociación" (La Prensa, 23 de agosto de 1971). Esta posición fue oficializada el 27 de agosto, al declarar la Cancillería altiplánica que está dispuesta a restablecer relaciones con Chile, siempre y cuanto este reconozca "el derecho boliviano a una salida propia y soberano al Océano Pacífico y a la solución favorable del problema del río Lauca" (El Mercurio, 28 de agosto de 1971).

En Naciones Unidas, el representante boliviano propuso el 7 de octubre una salida al mar, a intercambiar por "compensaciones geográficas no territoriales", como agua dulce, petróleo del oriente boliviano o la corriente comercial de los departamentos de Oruro, Cochabamba y Santa Cruz. Al día siguiente, en respuesta, el embajador chileno Díaz Casanueva expresó: "Recojo positiva la idea del canciller Gutiérrez de que Bolivia desea la conversación directa, el diálogo esclarecedor... Chile desea el diálogo y propone el restablecimiento de relaciones diplomáticas sin condiciones" ( $E l$ Mercurio, 9 de octubre de 1971). En forma sorpresiva, el canciller boliviano Mario Gutiérrez coincidió en que el "solo hecho de hablar de condiciones entorpece los entendimientos" y que lo que interesa "es lograr con Chile un entendimiento superior, que ponga fin a los problemas que tenemos entre ambas naciones", si bien ello mismo "no supone reanudación inmediata de relaciones diplomáticas" (El Mercurio, 14 de octubre de 1971).

El gobierno boliviano volvió a la carga en diciembre, cuando el canciller boliviano hizo una declaración en que se traía el espectro de un posible enfrentamiento: "Al precio de evitar una guerra es preciso, más bien, que busquemos una 
solución pacífica y constructiva”. Recomendó la creación de una comisión mixta que propusiera estudiar "fórmulas para poner fin a sus diferencias, satisfaciendo Chile sus necesidades y Bolivia sus aspiraciones" (El Mercurio, 9 de diciembre de 1971). Proponía que Chile entregase 12 mil kilómetros cuadrados en el Departamento de Arica, a cambio de compensaciones no territoriales. El subsecretario de Relaciones Exteriores de Chile, Aníbal Palma, respondió que su país tenía buena disposición para discutir los problemas bilaterales y que la comisión mixta era vista como una "posible medida acertada" (El Mercurio, 15 de diciembre de 1971). Tal respuesta se tomó en Bolivia como una proposición "para discutir y resolver los problemas fronterizos con Bolivia", lo que llevó a Palma a hacer un desmentido oficial de ciertas versiones cablegráficas de sus dichos (El Mercurio, 16 de diciembre de 1971).

Paralelamente, el gobierno boliviano hizo algunas gestiones confidenciales para tratar de reabrir las negociaciones. A fines de noviembre de 1971, el canciller Gutiérrez conversó con el excanciller Gabriel Valdés, de visita en La Paz. El chileno le comentó que la única solución posible para la mediterraneidad era un corredor que no implicara soberanía plena, para evitar objeciones por parte de Perú. Ante consultas posteriores, para saber si su planteamiento era apoyado por el gobierno chileno, Valdés expresó que el suyo era de carácter personal, sin conocimiento de La Moneda, comentándoles además a los bolivianos que por los problemas políticos y económicos que afectaban al gobierno de Allende, no era recomendable iniciar conversaciones sobre la cuestión del mar (Gumucio Granier, 1985, pp. 540-541).

\section{Conflicto ideológico}

A la controversia por la cuestión marítima, los gobiernos de Allende y Banzer también se enfrascarían en problemas derivados de sus diferencias ideológicas, con acusaciones de lado y lado de injerencias en los asuntos internos de cada país.

Un primer motivo de controversia surgió con motivo de la llegada de un número significativo de exiliados bolivianos a Chile (Palomera y Norambuena, 2018). El 3 de enero de 1972, el ministerio del Interior boliviano denunció que desde Chile ingresaban dólares falsos, parte de un "plan subversivo contra el gobierno nacionalista", apuntando a los exiliados bolivianos residentes en Chile (El Mercurio, 6 de enero de 1972). En febrero, el propio presidente Banzer se sumó a la acusación, expresando al New York Times que desde "Chile se ha constituido en una base de hostilidad política hacia Bolivia, con fomento desde Cuba... [Chile] parece empeñado en organizar nuevamente cuadros guerrilleros o cuando menos, terroristas que vengan a perturbar la vida nacional" (Tribuna, 11 de febrero de 1972). El gobierno chileno respondió defendiendo el derecho de asilo (El Siglo, 10 de febrero de 1972).

Durante un mitin político, ante un público que coreaba "en Bolivia se cayó porque al pueblo no se armó", Allende expresó que "la irresponsabilidad de los que no supieron dar un contenido a la Asamblea Popular en Bolivia hicieron que el imperialismo y la reacción derrumbaran al gobierno de Torres". Ello causó malestar en Bolivia, donde se contestó que, por ser un gobierno nacionalista, "no se inmiscuye en los asuntos internos de otros países y es respetuoso de la libre autodeterminación de sus pueblos" ( $E l$ Mercurio, 10 de enero de 1972).

En junio se declaró que ambos países habían llegado a un acuerdo para formar la comisión mixta que revisase los problemas entre ambas naciones, sin condiciones de ninguna clase (El Mercurio, 24 de junio de 1972). Desde Bolivia se indicó que podrían darse las condiciones para reanudar las relaciones en el curso de las reuniones de la comisión (El Mercurio, 13 de julio de 1972). Esta comenzó a funcionar el 7 de agosto de 1972, si bien su temario fue exclusivamente económico, en particular los temas relativos a la integración subregional andina (El Mercurio, 8 de agosto de 1972). Al terminar sus trabajos, se dieron algunos acuerdos para incrementar el intercambio comercial y avanzar hacia la complementación industrial (El Mercurio, 11 de agosto de 1972). Tras el entendimiento, el canciller boliviano Mario Gutiérrez dijo que ambos países "tienen miras a un futuro entendimiento superior" (El Mercurio, 12 de agosto de 1972).

Pero volvieron a surgir controversias por motivos ideológicos, publicándose versiones de prensa que denunciaban la actuación de Bolivia en planes subversivos contra el gobierno chileno, en particular respecto de las actividades del exmayor del Ejército de Chile, Arturo Marshall, exiliado en el país altiplánico (El Mercurio, 21 de septiembre de 1972). Junto con el desmentido boliviano, en diciembre ese gobierno relanzó la acusación de que había sectores guerrilleros bolivianos que conspiraban desde Chile, apuntando específicamente al exmayor de Ejército Rubén Sánchez (El Mercurio, 23 de diciembre de 
1972). En abril de 1973 también hubo una controversia por tres chilenos detenidos en Bolivia, que acusaron habían sido objeto de tortura por parte de la policía de ese país, que buscaba confesaran que se dedicaban a actividades subversivas (El Mercurio, 19 de abril de 1973).

Durante la celebración de la semana del mar en La Paz en marzo de 1973, el canciller boliviano expresó que su país estaba dispuesto a un diálogo para una reanudación de las relaciones diplomáticas, sin condiciones previas (El Mercurio, 22 de marzo de 1973). En una línea algo diferente se encontraba el discurso del vicecanciller Céspedes Rivera, que aunque pedía un diálogo abierto, dijo que "no puede ser eterno el Tratado de 1904 que privó a nuestro país de su amplio litoral sobre el Pacífico" (El Mercurio, 21 de marzo de 1973). Desde Chile se respondió que existía la mejor disposición para abrir un diálogo hacia Bolivia, aunque remarcando la validez e intangibilidad del tratado de 1904, como un compromiso libremente adquirido entre ambos países (El Mercurio, 21 de marzo de 1972).

Las relaciones parecieron encontrar un nuevo escollo al fracasar la comisión mixta portuaria con la que Bolivia trataba de mejorar sus condiciones de movimiento de carga por puertos chilenos. Se acusó intransigencia por parte de la delegación de Chile, lo que llevó al gobierno boliviano a anunciar que en adelante se prescindiría de esos puertos para su comercio exterior, para remplazarlos por Matarani e Ilo (El Mercurio, 30 de marzo de 1973). Desde Santiago se dijo que hubo un acuerdo en los principales puntos de la comisión, pero que hubo una posición negativa de los representantes bolivianos, "lo que podría interpretarse como una actitud deliberada a fin de adecuarla a la posición internacional que... viene siguiendo la Cancillería de La Paz con respecto a Chile" (El Mercurio, 5 de abril de 1973).

Al final del gobierno de Allende se hicieron nuevas gestiones para lograr un entendimiento y reanudar las relaciones (La Prensa, 28 de agosto de 1973). El momento clave fue una reunión de los cancilleres de los países del Pacto Andino, realizada en agosto de 1973, en donde los cancilleres Orlando Letelier y Mario Gutiérrez realizaron una discusión acerca de las diferentes alternativas a la cuestión portuaria, como antesala a una reunión de alto nivel a efectuarse en Cochabamba el 14 de octubre. En preparación, los bolivianos elaboraron un temario con las diferentes alternativas que consideraban para alcanzar su aspiración. El punto principal era una entrega de territorio con soberanía o, en caso de oposición peruana, con derecho a usufructo a perpetuidad. Los bolivianos no consideraban viable construir un puerto, por sus altos costos y dificultades geográficas, sino que esperaban utilizar libremente los puertos de esa ciudad. En caso de que no prosperase esta última idea, se pedía analizar la posibilidad de un enclave en Iquique o Mejillones. Respecto de las posibles compensaciones, se consideraba la venta de electricidad y la creación de empresas binacionales (International Court of Justice, 2017, vol. 4, p. 934-947). Cualquier posible avance quedó interrumpido por el golpe de Estado del 11 de septiembre de 1973, que puso fin al gobierno de Salvador Allende.

\section{Conclusión}

La revisión documental nos aclara el panorama respecto de la efectiva política exterior de Allende hacia Bolivia, lejana de la imagen idealista que algunos han pretendido instalar, de un Allende deseoso de dar mar a Bolivia en favor de un espíritu latinoamericanista (Taboada, 2005). En contraste, nos encontramos con una mezcla de pragmatismo e ideología. El problema de la demanda marítima boliviana nunca fue un tema central en el discurso previo de Allende ni se definió abiertamente en favor o en contra, pero, llegado a La Moneda, siguió una política que continuaba en parte la de su predecesor, de reanudar las relaciones diplomáticas a cambio de abrirse a discutir la aspiración marítima, con vistas a posibles beneficios económicos para Chile, enmarcado en el respeto a los tratados. Aprovechó la cercanía ideológica de los dos gobiernos para avanzar en la negociación, al facilitarse la creación de confianzas entre personeros de ambos gobiernos. La caída de Torres y la llegada de un régimen ideológicamente hostil en la figura de Hugo Banzer, tensionó las relaciones. El antagonismo ideológico se mostró en una reanudación de la demanda portuaria y acusaciones de intervencionismo chileno en Bolivia, pero La Moneda continuó tratando de encontrar un modo de resolver las tensiones, a pesar de las acusaciones recíprocas de interferencia en los asuntos internos, sin ceder a las demandas por reabrir el tema marítimo de manera forzada.

\section{Agradecimientos}

Deseamos agradecer a la Biblioteca del Congreso Nacional por su ayuda en la recolección de las fuentes y a los evaluadores por sus comentarios al texto. 


\section{Referencias Citadas}

Biblioteca Clodomiro Almeyda

2014 Archivo Parlamentario Salvador Allende (APSA), tomo III, https://www.socialismo-chileno.org/PS/APSA/ (accedido el 5 de marzo de 2020).

Biblioteca Clodomiro Almeyda

2015 Archivo Parlamentario Salvador Allende (APSA), tomo VIII, https://www.socialismo-chileno.org/PS/APSA/ (accedido el 5 de marzo de 2020).

Allende, S.

1978 Salvador Allende y América Latina: 12 discursos y 2 conferencias de prensa. Casa de Chile en México, México.

Almeyda, C.

1971 "Discurso pronunciado por el ministro de Relaciones Exteriores, Clodomiro Almeyda, en la Asamblea General de la Organización de Estados Americanos, 15 de abril de 1971”, Estudios Internacionales, Vol. 4 Núm. 16.

Belmonte Pijuán, M.

2012 Repercusiones de la gestión de falange socialista boliviana en la política exterior boliviana respecto de la demanda marítima nacional (1971-1973). Tesis. Universidad Mayor de San Andrés.

Fermandois, J.

1985 Chile y el mundo, 1970-1973. La política exterior del gobierno de la Unidad Popular y el sistema internacional. Ediciones Universidad Católica de Chile, Santiago.

Gumucio, G.

1985 Estados Unidos y el mar boliviano. s/e., Nueva York. International Court of Justice

2007 Reply of the Plurinational State of Bolivia, Vol. 3 y 4.

Magasich, J

2014 "Bolivia y el mar. Negociaciones boliviano-chilenas entre los gobiernos de Juan José Torres y Salvador Allende, en 1971”. Le Monde Diplomatique, Diciembre.
Otero, J. L. y Rivas, P.

2018 "El imaginario social marítimo boliviano. Una explicación social de la política exterior de Bolivia hacia Chile". Diálogo Andino № 48.

Ovando, C.

2015 "La noción de soberanía en las propuestas bolivianas para la salida al mar: El caso Arica trinacional". Diálogo Andino $\mathrm{N}^{\circ} 48$.

Palomera, A. y Norambuena, C.

2018 "Refugio y asilo de bolivianos durante la dictadura chilena entre 1973 Y 1975". Diálogo Andino No 57.

San Francisco, A. et al.

2016 Historia de Chile 1960-2010, Tomo 2. CEUSS, Santiago.

San Francisco, A. et al.

2018 Historia de Chile 1960-2010, Tomo 3. CEUSS, Santiago.

San Francisco, A. et al.

2019 Historia de Chile 1960-2010, Tomo 5. CEUSS, Santiago.

Sánchez Fuentes, R.

2015 Pueblo, continente y revolución. La construcción de América Latina en el discurso de Salvador Allende. Editorial América en Movimiento, Santiago.

Taboada, N.

1971 Chile con el corazón a la izquierda. Editorial Universitaria, Oruro.

Taboada, $\mathrm{N}$.

2004 Salvador Allende ;mar para Bolivia! Plural Editores, La Paz.

Yofre, J. B.

2000 Misión argentina en Chile (1970-1973). Los registros secretos de una difícil gestión diplomática. Editorial Sudamericana, Santiago.

\section{Notas}

$1 \quad$ Mensaje presidencial, 21 de mayo de 1971. 